Voix et Images

voixetimages

\title{
Une figure du pouvoir : le chef piégé
}

\section{Andrée Mercier}

Volume 12, numéro 3 (36), printemps 1987

Yves Beauchemin

URI : https://id.erudit.org/iderudit/200667ar

DOI : https://doi.org/10.7202/200667ar

Aller au sommaire du numéro

Éditeur(s)

Université du Québec à Montréal

ISSN

0318-9201 (imprimé)

1705-933X (numérique)

Découvrir la revue

Citer cet article

Mercier, A. (1987). Une figure du pouvoir : le chef piégé. Voix et Images, 12(3), 534-538. https://doi.org/10.7202/200667ar d'utilisation que vous pouvez consulter en ligne.

https://apropos.erudit.org/fr/usagers/politique-dutilisation/ 


\title{
Une figure du pouvoir: le chef piégé
}

\author{
par Andrée Mercier, Université du Québec à Montréal
}

\section{Du document au témoignage}

On analyse de moins en moins les relations de voyage comme de simples documents. Plus circonspect, le chercheur anthropologue, historien, philosophe ou autre, dépiste derrière l'information un intermédiaire longtemps occulté: le témoin qui observe la réalité et qui ne peut la décrire qu’à partir de sa subjectivité, aussi retenue soit-elle. Ainsi, les récits entourant une conquête participent d'abord à un processus de colonisation: ils peuvent constituer simultanément un argument en faveur de l'entreprise coloniale, un répertoire des connaissances nécessaires à sa poursuite, un compte rendu d'observations davantage gratuites et le témoignage d'une expérience personnelle. Par exemple, Christophe Colomb souligne constamment la présence de l'or et l'immense potentiel d'esclaves indiens pour convaincre les "investisseurs" de maintenir leur soutien, tout comme il prend plaisir à décrire à profusion une nature qui semble l'enchanter pour elle-même. Les Indiens n'ayant pas retenu vraiment l'attention de l'explorateur en dehors de leurs possibles valeurs 
marchandes, Todorov remarque avec perspicacité que Colon [sic] a découvert l'Amérique mais non les Américains'.

L'essai de Jean-Marie Therrien ${ }^{2}$ aborde justement les écrits de la Nouvelle-France comme autant d'éléments d'un vaste savoir nécessaire à une politique de conquête "plus ou moins brutale». Au cœur de ce réservoir de descriptions, un acteur occupe une position stratégique: le chef amérindien, médiateur obligatoire entre les communautés autochtones et les représentants coloniaux. Therrien montre bien l'enjeu qui se cache derrière une description exhaustive du chef. Alors que les premiers contacts se limitaient à entrevoir un chef sans pouvoir coercitif, peu autoritaire et même sujet de moquerie pour ses semblables, seule une observation moins approximative peut élaborer un savoir utilisable. En effet, cette figure très sommaire n'indique pas aux colonisateurs comment entrer en rapport avec les chefs amérindiens, elle ne leur dit pas non plus si l'on peut signer un traité avec l'un d'eux et si l'on peut espérer que ce traité soit respecté par les membres de sa communauté (p. 22). De nombreux récits viendront bientôt développer cette toute première perception du chef. En trois siècles, missionnaires, administrateurs et voyageurs en Nouvelle-France fourniront de nombreux témoignages sur la réalité autochtone, descriptions quelquefois discordantes. Ainsi, une meilleure connaissance de la société politique amérindienne sert d'abord d'argument au projet colonisateur et missionnaire qui se trouve justifié de détruire un espace social primitif sans forme d'autorité et dominé par le désir et l'instinct. Parallèlement, cette même description alimente tout autant une critique de la structure monarchique en prouvant la possibilité pour un groupe humain de vivre sans règle ni discipline.

Therrien montre bien que la société amérindienne était rarement observée pour elle-même. Mais il ne peut lui-même échapper à l'engrenage inévitable du discours scientifique moderne qui, lui aussi, utilise l'Indien comme prétexte à des considérations d'un autre ordre. Il choisit donc franchement de renouer avec la tradition des philosophes voyageurs: appréhender l'Indien pour mieux se comprendre, se connaitre soi-même (p. 17). Soi-même recouvre d'abord le voyageur-narrateur des siècles passés et implique la reconstitution de ses valeurs. Mais soi-même désigne aussi le lecteur moderne fatalement convoqué par ces récits et le genre de société qu'ils proposent. Toutefois, contrairement à Todorov qui abordait les récits de voyage entourant la conquête du Mexique et des Caraïbes avec une intention éthique - à travers une histoire exemplaire, trouver une réponse au problème du comportement avec autrui -, Therrien laisse au lecteur le soin de réfléchir sur ses propres valeurs et de les évaluer. Toujours dans la tradition des philosophes-voyageurs, l'essai a aussi comme fin de donner cohérence et intelligibilité à un espace étranger, celui du chef huron et iroquois. Il s'agit d'un travail de reconstitution d'une figure idéale du chef amérindien, travail qui vise à saisir et à transmettre toutes les significations du rôle de chef. Therrien veut en quelque sorte pallier au regard culturel nécessairement étroit des Relations des Jésuites, par exemple, où la volonté de savoir est volonté de pouvoir (p. 45). Il reconstitue morceau par morceau les fonctions caractéristiques du chef et tente de rendre compréhensible l'organisation sociale qu'elles recouvrent. 
Il s'agit en somme d'interpréter les descriptions contenues dans ces récits, de s'en tenir essentiellement au discours blanc. L'Indien reste toujours muet, il ne prend que la parole qu'on veut bien lui prêter... Et malgré une introduction prudente sur l'idéologie qui façonne les écrits de la Nouvelle-France, Therrien oublie trop souvent de nuancer les propos que les Jésuites, entre autres, attribuent aux Indiens. Dans les textes, on retrouve un peu partout un discours de totale soumission adressé par des chefs à certains missionnaires:

Mon frère, aie pitié de ce pays. Toi seul peux lui rendre la vie. C'est à toi de rassembler ces ossements épars. C'est à toi qu'il appartient de fermer l'abime ouvert pour nous engloutir. Aie pitié de ton pays: nous l'appelons ton pays, car nous t'en reconnaissons le maître.

Voici mon fils que je te donne pour te faire connaître mon cour, je te prie d'avoir pitié de moi et de toute ma nation. C'est toi qui connaît le grand Génie qui nous a tous faits, c'est toi qui lui parles et qui écoutes sa parole, demande-Lui qu'il me donne la vie et la santé et viens demeurer avec nous pour nous Le faire connaître.

(p. 143-144)

Therrien voit dans ces paroles une rhétorique du chef indien pour maintenir par une subordination flatteuse l'alliance commerciale et militaire avec les Français. Si l'interprétation se justifie, elle ne peut occulter le phénomène de substitution narrative: le missionnaire-narrateur peut très facilement attribuer à l'Indien les propos qu'il veut bien lui entendre dire. La rhétorique se situerait alors du côté de l'énonciateur du récit qui, somme toute, a le dernier mot de l'histoire. Promouvoir les valeurs chrétiennes, démontrer l'aptitude à la conversion des Indiens, insister sur leur fidélité ne sont qu'autant de moyens pour rassurer les bienfaiteurs actuels et éventuels de l'entreprise coloniale. Les relations de Champlain et de Gabriel Sagard rapportent fréquemment ce même type de propos presque trop beaux pour être vrais! D'ailleurs, en dernière analyse, les actes de soumission valorisent surtout le narrateur qui en sort empreint d'une autorité... toute rhétorique. Ce genre de substitution va aussi de pair avec l'habitude de taire ses sources. Très souvent les narrateurs de l'époque racontent des événements auxquels ils n'ont tout simplement pas assisté mais qu'ils reconstituent à partir de récits entendus ou lus. Là encore, Therrien oublie de se méfier de ses sources. Le récollet Sagard, contrairement à ce qui est affirmé à la page 241 , ne peut pas constituer le témoin de la fête de 1632 puisqu'il était présent en Huronie quelque neuf années plus tôt, en 1623-1624. Il rapporte donc tout au plus un témoignage auriculaire de la fête.

\section{Le chef gardien des coutumes ancestrales}

Le dépouillement des nombreuses sources écrites débouche sur une figure dominante du chef amérindien: le gardien des coutumes ancestrales. C'est grâce au respect scrupuleux des rituels, des coutumes, des croyances religieuses, des mythes et des savoir-faire immémoriaux que l'ordre social est maintenu (p. 303-304). Le chef doit connaître parfaitement les moyens prescrits par la mémoire collective pour contrer tout bouleversement: maladie, 
injustice, mort, guerre. Par exemple, les ceintures de coquillage que l'on s'échange lors des rencontres constituent justement une sorte d'archives du savoir, dont le chef est le dépositaire et le lecteur. Dans les faits, le pouvoir politique du chef ne se rapporte pas à un seul individu. Plusieurs instances se partagent la responsabilité de l'ordre social: un chef civil, un chef de guerre, le conseil des anciens, les matrones et les shamans. À cela s'ajoute une conception non coercitive du pouvoir. Le chef fonde son autorité sur la persuasion, son principal outil étant la parole. Therrien insiste sur le caractère fondamental de la réalité politique amérindienne: le lieu de l'habileté politique du chef se situe dans sa parole, aucune transmission héréditaire du pouvoir ni aucun statut permanent ne prévaut, le choix du chef est fondé sur l'estime et l'adresse de l'individu. Therrien s'attarde particulièrement à la fête qu'il présente comme une véritable affaire d'état. Toujours dirigée et commandée par le chef, la fête a diverses manifestations. La fête des songes, par exemple, suit le même principe que le carnaval puisqu'elle institutionnalise le désordre pour mieux restaurer la stabilité sociale et politique. La fête des morts va encore plus loin en terme de valeur politique; elle réunit plusieurs tribus et permet de raffermir l'unité de la nation et aussi d'affirmer cette alliance aux nations alliées. Les différentes sortes de fête apparaissent comme l'instrument et la responsabilité essentiels du pouvoir politique du chef amérindien. Therrien remarque justement l'incompatibilité entre les valeurs chrétiennes et de telles fonctions. Les missionnaires condamnent avec vigueur la fête, dans laquelle ils ne voient qu'une réjouissance primitive. La figure du chef converti reste rare et peu orthodoxe puisqu'elle recouvre la réalité la plus opposée au statut de chef: comment concilier le refus de la fête et la garantie des coutumes ancestrales?

\section{La figure du chef piégé}

La reconstitution du rôle du chef s'appuie sur une interprétation des récits. C'est l'auteur qui organise en une structure un acteur d'abord morcelé et décrit partiellement ici et là dans les textes. Si on recherche des renseignements sur le chef des Natchez, il nous faudra lire les Relations des pères Gravier et Le Petit, L'Histoire de la Nouvelle-France du père Charlevoix, les Nouveaux Voyages en Louisiane de Bossu, enfin certaines pages des Moeurs des Sauvages américains comparées aux moeurs des premiers temps de Lafitau (p. 29-30). La figure du chef gardien des coutumes ancestrales correspond donc à un travail de cueillette et à un premier niveau d'induction. Toutefois, une autre figure du chef déjà plus abstraite finit par se surimposer à la première: le chef piégé. Cette nouvelle représentation du chef n'est jamais clairement définie par Therrien, elle se glisse plutôt au fil de l'ouvrage dans une série d'affirmations dont l'ampleur en arrive à frapper le lecteur:

Les sociétés huronnes et iroquoises ont adopté une stratégie pour piéger leurs chefs dans l'exercice de leur pouvoir et de leurs fonctions. Cette structuration du pouvoir s'obtient d'abord en limitant son mode d'exercice à la persuasion, en instituant des surveillants des chefs, en organisant des conseils de village et des assemblées générales investis d'un pouvoir exécutif.

(p. 81-82) 
Le prestige est un piège, il comporte autant d'honneurs que de responsabilités.

Mais qui est le plus piégé dans cet échange [la redistribution des biens ]? Si la prodigalité du chef diminue, les «sujets» cessent de lui rendre hommage, l'accusent de parcimonie, le démettent de ses fonctions. Si les hommages des «sujets" se font moins nombreux, la prodigalité du chef doit se manifester avec encore plus d'éclat.

Therrien dégage, minutieusement, derrière chaque fonction et privilège du chef, des obligations, des limites à son pouvoir. Le chef est piégé parce que soumis au contrôle social: la structure politique amérindienne ne lui permettrait pas de tomber dans l'avidité et la soif démesurée de pouvoir. Le chef de guerre est ainsi responsable de la vie de tous ses guerriers, devoir qui aide le chef civil et les anciens à contrer les entreprises de guerre trop aventureuses. De même, les discours que le chef prononce doivent toujours représenter la société ou les individus menacés, puisque la société amérindienne utilise l'éloquence de ses chefs, elle situe hors d'eux l'objet de leur discours (p. 109). La société amérindienne est présentée comme un habile stratège en matière de pouvoir politique. Une telle figure convoque inévitablement l'essence du pouvoir politique occidental; sujet de réflexion donc. Mais elle est surtout l'objet d'un acte d'écriture, d'une reconstitution idéale qui l'extirpe du discours (les récits passés) pour aussitôt l'y remettre. Jadis enjeu cognitif d'un projet colonial et missionnaire, le chef amérindien se retrouve maintenant au coeur d'une démarche intellectuelle qu'on prend plaisir à... reconstituer!

1. Tzvetan Todorov, la Conquête de l'Amérique. La question de l'autre, Paris, Seuil, 1982 , p. 54.

2. Jean-Marie Therrien, Parole et pouvoir. Figure du chef amérindien en NouvelleFrance, Montréal, Éd. de l'Hexagone, 1986, 325 p. (Coll. "Positions anthropologiques"). Les références à l'ouvrage seront désormais indiquées entre parenthèses après les citations. 